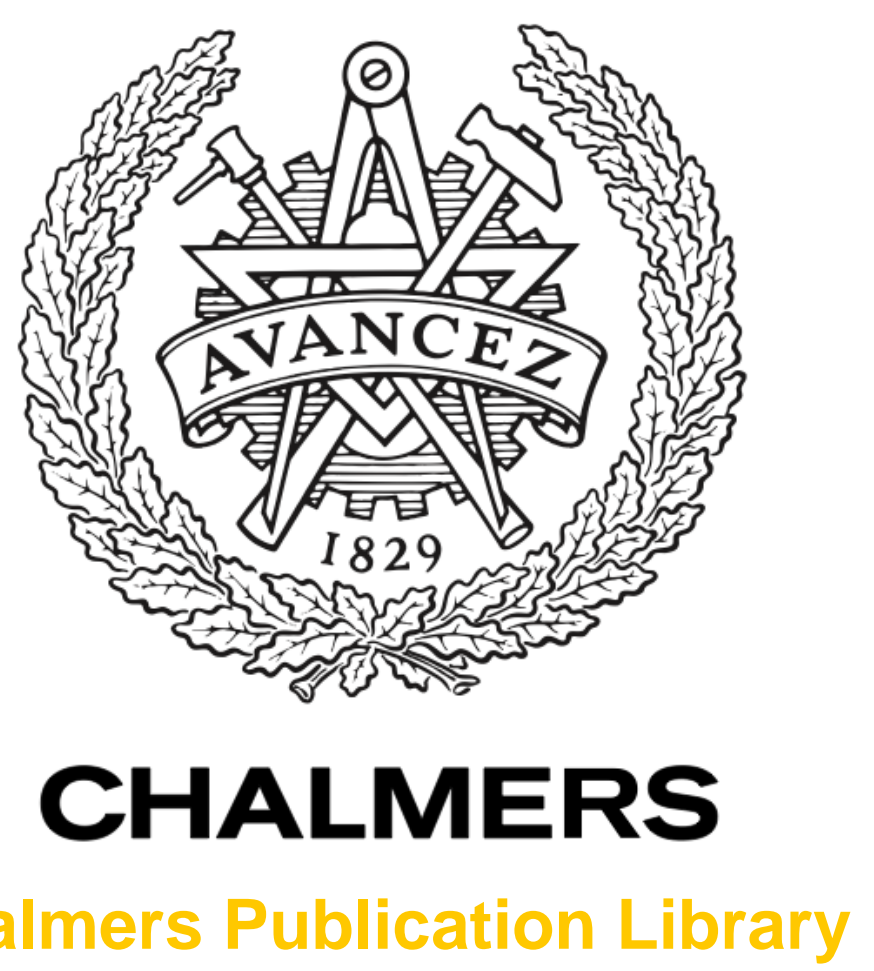

\title{
Clinical decision support system (CDSS) - effects on care quality
}

This document has been downloaded from Chalmers Publication Library (CPL). It is the author's version of a work that was accepted for publication in:

International journal of health care quality assurance/MCB University Press (ISSN: 0952-

6862)

Citation for the published paper:

Santos, M. ; Tygesen, H. ; Eriksson, H. (2014) "Clinical decision support system (CDSS) effects on care quality". International journal of health care quality assurance/MCB

University Press, vol. 27(8), pp. 707-718.

Downloaded from: http://publications.lib.chalmers.se/publication/205092

Notice: Changes introduced as a result of publishing processes such as copy-editing and formatting may not be reflected in this document. For a definitive version of this work, please refer to the published source. Please note that access to the published version might require a subscription.

Chalmers Publication Library (CPL) offers the possibility of retrieving research publications produced at Chalmers University of Technology. It covers all types of publications: articles, dissertations, licentiate theses, masters theses, conference papers, reports etc. Since 2006 it is the official tool for Chalmers official publication statistics. To ensure that Chalmers research results are disseminated as widely as possible, an Open Access Policy has been adopted.

The CPL service is administrated and maintained by Chalmers Library. 


\section{Clinical decision support system (CDSS) - effects on care quality}

Author 1: Marco António Ferreira Rodrigues Nogueira dos Santos, Division of Quality Sciences/Centre for Healthcare Improvement, Chalmers University of Technology, Gothenburg, Sweden

Author 2: Hans Tygesen, Department of Cardiology, Södra Älvsborg Hospital, Borås, Sweden Author 3: Henrik Eriksson, Department: Division of Quality Sciences/Centre for Healthcare Improvement, Chalmers University of Technology, Gothenburg, Sweden

Author 4: Johan Herlitz, Centre of Pre-hospital Research in Western Sweden, University of Borås and Sahlgrenska University Hospital, Gothenburg, Sweden

Corresponding author: Marco António Ferreira Rodrigues Nogueira dos Santos

Corresponding Author's Email: marco.santos@chalmers.se

Acknowledgments: The authors thank Associate Professor Ulla Blomqvist for her statistical assistance, Adjunct Professor Bengt-Arne Sjöqvist, Annica-Ravn Fisher, Bo Hallin and Susanne Gustavsson for their insights and comments.

\section{Structured Abstract:}

Purpose: Despite their efficacy, certain recommended therapies are underused. This study describes a clinical decision support system's (CDSS) development and its impact on clinical guideline adherence.

Design/Methodology/Approach: A new CDSS was developed and introduced in a cardiac intensive care unit (CICU) in 2003, which provided physicians with patient-tailored reminders and permitted data export from electronic patient record (EPR) into a national quality registry. To evaluate the CDSS effects in the CICU, process indicators were compared to a control group using registry data. All CICUs were in the same region and only patients with acute coronary syndrome were included.

Findings: The CDSS's introduction was associated with increases in guideline adherence, which ranged from $16 \%$ to $35 \%$, depending on the therapy. Statistically significant associations between guideline adherence and CDSS use remained over the five-year period after the CDSS introduction. During the same period, no relapses occurred in the intervention CICU.

Practical implications: Increased guideline adherence and improved healthcare quality can be enhanced using CDSS. This study suggests that practitioners should turn to CDSS to improve healthcare quality.

Originality/value: This article describes and evaluates an intervention that successfully increased guideline adherence that improved healthcare quality when the intervention CICU was compared to the control group.

Keywords: Clinical guidelines, Decision making, Quality healthcare, Evidence-based practice, Quality improvement

Article Classification: Research

Received $-19^{\text {th }}$ January 2013

Revised $-23^{\text {rd }}$ Jan 2014 


\section{Accepted -}

\section{Introduction}

Unwarranted variation (Wennberg, 2002) and its potentially detrimental consequences manifested as underused, overused or misused treatment and care (Chassin and Galvin, 1998) has propelled evidence-based medicine (Sackett et al., 1996). Consequently, clinical practice guidelines have been developed and made available to healthcare providers who adhere to these guidelines by varying degrees (Davis and Taylor-Vaisey, 1997; Cabana et al., 1999; Eagle et al., 2003). Reminder systems are among the most effective tools for increasing guideline adherence (Grimshaw et al., 2001; Sipkoff, 2003; Prior et al., 2008) but their effectiveness seems neverthless to vary greatly; e.g., point-of-care computer reminders generally yield merely small to modest care improvements (Shojania et al., 2010). Reminder systems can be classified as a clinical decision support system (CDSS) since they use patient data to generate case-specific advice (Wyatt and Liu, 2002). Consequently, we describe how a cardiac intensive care unit (CICU) point-of-care computer reminder system was developed and introduced. We evaluate CDSS effects on clinical practice and healthcare quality by investigating changes in guideline adherence regarding five quality indicators.

\section{Theory}

Decision-making can be aided by CDSSs in various ways as these systems exhibit extensive heterogeneity in design, function and use (Payne, 2000; Coiera, 2003; Berlin et al., 2006). The aid provided by CDSSs and subsequent gains in quality improvement are especially relevant to medication errors (Hunt et al., 1998; Garg et al., 2005; Kawamoto et al., 2005; Shedlbauer et al., 2009). Nevertheless, CDSSs also pose challenges as they may cause additional errors; e.g., inappropriately using default doses (Reckmann et al., 2009). The CDDS's effectiveness is usually higher in managerial rather than for diagnostic contexts (Grol and Grimshaw, 2003). Their effectiveness also tends to be high for preventive care (Dexter et al., 2001). The CDSS effects on patient outcomes have been insufficiently studied and they are inconsistent (Garg et al., 2005). Likewise, CDSS cost effectiveness remains unknown (Garg et al., 2005). Several factors may hinder CDSS use and its potential; e.g., initial investment, number of reminders, previous information-technology (IT) failures, concerns about the physician-patient relationship, threats to professional autonomy and poor links in and between systems (Bates et al., 2001; Bates et al., 2003; Varonen et al., 2008). Despite multiple barriers, physician perceptions remain relatively positive (Varonen et al., 2008). Most CDSSs are home grown and their performance improves in cases when healthcare personnel develop the CDSSs (Garg et al., 2005). Moreover, there needs to be a run-in period during which there may be a decrease in productivity (Coiera, 2003).

\section{Methodology}

The intervention we describe occurred in the cardiac and pulmonary department located in Borås, Sweden (the intervention CICU). The intervention concerned exclusively patients with acute coronary syndrome and only cardiology specialists were thus involved in the intervention. The intervention CICU belongs to the Southern Älvsborg Hospital (Skaraborg, 2012), which provides care to approximately 285,000 inhabitants in Västra Götaland (West Sweden) region (VGR, 2012) - population 1.6 million. The intervention CICU in 2003 had 20 beds as was staffed by two specialists and two assistant physicians at a time. The two specialist positions 
were shared by six doctors. Over a year, about 20 doctors served as assistant physician. As the intervention CICU had joined the national quality registry described below, a link between EPR and the registry database was needed to avoid redundant data. A senior physician (a co-author) working in the intervention CICU proposed creating a link and envisioned developing an IT system to support clinicians in their daily practices by providing reminders about recommended care specifically tailored to their patients. The new IT system was expected to eliminate unwarranted clinical-practice variations and promote guideline adherence among physicians. The IT system was named Hjärtjournalen; i.e., the heart records (HRs). Their development took approximately 16 months and required three full-time equivalent (FTE) IT developers and a 0.25 FTE physician to specify functional requirements and to test trial versions. The HRs were launched in the CICU in 2003. Initially, several physicians resisted using the HRs as they perceived them to question their competence. Some physicians also objected the guidelines promoted by the HRs and others warned about the risks inherent in adhering to guidelines only intended to improve the intervention CICU rankings in the annual comparative reports issued by the national quality registry or for avoiding having to explain deviations from guidelines. Moreover, the HRs required physicians to enter data about the care they delivered rather than traditional dictaphone recording and subsequent transcription into the EPR by medical secretaries. The physicians decided nonetheless to give the HRs a try provided that their use remained voluntary. After a one-week trial period, the HRs were suspended to correct their flaws. The revised HRs were launched within a few weeks and have been used continuously, and is well disseminated among CICU physicians. Over time, the system has developed.

\section{HRs}

The intervention resulted in an IT system that supports clinical operations in the CICU by providing patient-tailored messages about the patient's current health status, baseline characteristics and national guidelines. If physicians deviate from the guidelines then the HRs notify them to undertake corrective measures or to motivate the deviation. By interacting with the EPR, the HRs permit treatment and care data export to the national quality registry. In their current form, the HRs include several modules; the core comprises patient background, overview, physician signing box, log-off and reports. The remaining modules concern specific treatments; e.g., coronary angiography, echocardiography and pacemaker. Both clinical practice guidelines and notifications can be reconfigured, which permits notifications to recruit patients to clinical trials. Deviation from guidelines notices can be provided in real time; i.e., feedback is given automatically whenever the physician enters data into the HRs or when actively requested, or in batches. Figure 1 shows an HRs screenshot (front window), which notifies that a deviation occurred: (1) and that ACE-inhibitor should be prescribed (2) according to the myocardial infarction and diabetes prevalence criteria. The notification solicits the reason for the deviation (3) according to known allergy, secondary effects, renal failure, hypotension or other. Comments can be inserted (4). The background screen displays the IT system name (5), existing modules (6), basic functions (7), service site (8), patient identifier (9) and user identification (10). Modules comprise several tabs and the module displayed comprises: baseline characteristics, general data, medical history, risk factors and care events (11).

\section{Figure 1 here}

\section{Databases and quality indicators}

Please note, we print footnotes and end notes only under exceptional circumstances. 
Data for assessing intervention effects were retrieved from the national quality registry RIKSHIA database (SWEDEHEART, 2012), which has existed for 20 years and ultimately aims to develop acute coronary care, decrease mortality and morbidity, and increase cost effectiveness. Registry-participating hospital staff report at least 100 predefined variables concerning patient admission, hospitalisation and discharge. Data are used for both longitudinal and cross-sectional studies. Data reliability and validity are discussed elsewhere (RIKS-HIA, 2005). We assessed the HRs effects using five quality indicators monitored by the registry: (i) coronary angiography performance in AMI patients without ST-elevation (\%COR); (ii) subcutaneous/intravenous Lmw-heparin or percutaneous coronary intervention within $24 \mathrm{~h}$ in AMI patients without STelevation (\%HEP); (iii) lipid lowering treatment after AMI (\%LIP); (iv) ACE-inhibitor/A2blocker treatment after AMI (\%ACE); and (v) clopidogrel after AMI without ST-elevation $(\% \mathrm{CLO})$. The indicators were expressed as the proportion of eligible patients prescribed a recommended therapy - a guideline adherence measure. The annual reports published by the registry provide additional details on these indicators (SWEDEHEART, 2012).

\section{Control group}

Control groups allow time-dependent factor influences (such as technological advancements, medication patents expiration and economic and political conditions) to be removed. Random patient allocation into a control group and an intervention group was infeasible in this study. Patients were assigned to the CICU according to their residence location and disease. Nonrandom allocation makes quasi-experiments more vulnerable to confounding (Bryman and Bell, 2007), which means that guideline adherence differences between the intervention CICU and the control group may depend on factors other than the HRs use. As the Swedish healthcare system is highly decentralised and heterogeneous, regionally economically and politically, the control group was restricted to all registry-participating CICUs located in the same region as the intervention CICU. The restriction on geographic location imposed on the control group increased internal validity as it decreased confounding risks. However, this act reduced external validity, making generalising the HRs effects to other regions more questionable. Table I shows the intervention CICU and control group characteristics. If patient data were missing then they were substituted with data on the inhabitants in the respective service areas. Concerning service range and patient disease severity, the intervention CICU was positioned somewhere in-between the control group extremes. For instance, the intervention CICU's catheterization laboratory (CathLab) was open exclusively during daytime whereas in the control group, there were: (i) CICUs with around-the-clock CathLabs; and (ii) CICUs without a CathLab.

\section{Table I here}

\section{Data collection and analysis}

The intervention's effects were studied retrospectively over time and in relation to a control group. The temporal analysis was divided into short-term; i.e., 2002-2004; and long-term; i.e., 2004-2008. The short-term analysis included comparing guideline adherence in 2004 and 2002 (the HRs were introduced in 2003). Analysing guideline adherence during the five-year period after the HRs introduction aimed at assessing the effects sustainability at the intervention CICU. The long-term analysis was expected to clarify reactivity bias (Grønmo, 2006, pp.51-52), as behavioural changes, prompted by the being observed, tend to disappear over time; i.e., individuals tend to relapse into old habits. Between 2004-2008, the HRs were available solely at 
the intervention CICU and their use was stable and comprehensive as all patients admitted to the intervention CICU were treated by physicians using the HRs. The long-term analysis also aimed at studying the changes in guideline adherence within the control group during the same period. Data extracted from the registry database included: total patients eligible and patients prescribed certain therapies: COR, HEP, LIP, ACE and CLO; year and provider (intervention CICU or control group). The quality indicator \%CLO was excluded from the short-term analysis as no $2002 \%$ CLO data were available. Since 2003 was a transition year, no data were collected. The control group used in the long-term analysis encompassed ten CICUs and because data were missing for 2002, the ten-unit control group was reduced to eight CICUs for the \%LIP and $\% \mathrm{ACE}$ quality indicators and seven CICUs for \%COR and \%HEP in the short-term analysis. The eight-unit and seven-unit control groups represented about $80 \%$ and $70 \%$, respectively, of eligible patients in the ten-unit control group.

\section{Measures and statistical analysis}

The HRs short-term effect in each quality indicator was estimated as the difference between the change scores in the intervention CICU vs. the control group. The change scores were calculated as the guideline adherence difference between 2004 and 2002. Differences in proportions were tested using chi-square. Change scores and estimated effects were expressed in percentages. Confidence intervals for the estimated effects were calculated using a one-sample t-test. The long-term effects, guideline adherence weighted averages in the intervention CICU vs. the control group, were calculated for five quality indicators studied during 2004-2008. Differences in proportions were tested using chi-square. Odds ratios and corresponding confidence intervals were obtained using multiple binary logistic regressions with the year included as a covariate. To check relapses, simple binary logistic regressions were performed on data referring to the intervention CICU, with guideline adherence as the independent variable and year as the dependent variable. To study the control group's guideline adherence compared to the intervention CICU during the same period, the proportion of the control group receiving the recommended treatment, if guideline adherence in the control group had been similar to the intervention CICU, was calculated for each year and quality indicator and used as an independent variable in simple binary logistic regressions with year as the dependent variable performed on data limited to the control group. All significance tests were two-tailed and statistical significance was set at the 0.05. All analyses used the IBM SPSS Statistics v.19.

\section{Findings}

\section{Short-term effects}

Table II and Figure 2 illustrate the short-term effects concerning four quality indicators. For each quality indicator, Figure 2 shows the guideline adherence in the control group and intervention CICU in 2002 and 2004 (pre and post intervention respectively). Column width is proportional to total patients eligible for each therapy. Seven-unit control groups were used for \%COR and $\% \mathrm{HEP}$, whereas for \%LIP and \%ACE, the control groups included eight CICUs. Preintervention guideline adherence concerning \%LIP at the intervention CICU was statistically significantly lower than the control group. Concerning the remaining quality indicators, no statistically significant differences were found in pre-intervention guideline adherence in the intervention CICU vs. control group. Post-intervention guideline adherence at the intervention CICU was statistically significantly higher than in the control group for all quality indicators. Adherence to guidelines in all quality indicators increased from 2002 to 2004 in the intervention 
CICU and the control group. Nevertheless, increases in the intervention CICU were more pronounced than the control group. Besides the increases in guideline adherence occurring in the control group, the intervention was associated with additional increases:

- $18 \%\left(\mathrm{CI}_{95 \%}=[11,25]\right)$ for $\% \mathrm{COR}$

- $16 \%\left(\mathrm{CI}_{95 \%}=[10,22]\right)$ for $\% \mathrm{HEP}$

- $35 \%\left(\mathrm{CI}_{95 \%}=[28,41]\right)$ for $\%$ LIP and

- $29 \%\left(\mathrm{CI}_{95 \%}=[22,36]\right)$ for $\% \mathrm{ACE}$.

All these increases were statistically significant $(\mathrm{p}<0.001)$ and rounded. The largest increase occurred for \%LIP, a quality indicator in which the intervention CICU performed considerably worse than the control group prior to the intervention.

\section{Table II and Figure 2 here}

\section{Long-term effects}

Table II and Figure 3 illustrate the HRs' long-term effects concerning five quality indicators. For each quality indicator, Figure 3 shows guideline adherence in the control group and intervention CICU between 2004-2008. Column width is proportional to total patients eligible for each therapy. Ten-unit control groups were used for all quality indicators. The thick horizontal lines represented a five-year weighted average guideline adherence in the control group and at the intervention CICU. Table II shows that the statistically significant differences in guideline adherence between the intervention CICU and the control group lasted during 2004-2008. The difference in guideline adherence was least for $\% \mathrm{HEP}$ and most for \%CLO. Guideline adherence continued to be associated with the HRs use over the five years after their introduction. Table II also indicates that, over time, the odds that patients treated in the intervention CICU were prescribed the recommended therapy increased for all quality indicators. However, these increases were statistically significant only for \%HEP and \%CLO. As no statistically significant decreases in guideline adherence could be found, the possibility of relapses can be ruled out. Finally, Table II shows that the odds that patients treated in the control group would have been prescribed the recommended therapy if guideline adherence in the control group had been similar to the intervention CICU decreased over time for all quality indicators. These decreases were statistically significant for all quality indicators and indicated that over time, guideline adherence in the control group approximated that in the intervention CICU.

\section{Figure 3 here}

\section{Discussion}

Significant improvements were found in all quality indicators when the intervention CICU was compared to the control group. These improvements were most pronounced in the short-term but persisted during the five years after the HRs introduction. The control group caught up during this five-year period, which suggested that guidelines were underused and that increases in guideline adherence represented increased care quality. Results suggested that the HRs accelerated research findings uptake into clinical practice. These results constituted further evidence that CDSSs affect clinical practice and promote guideline adherence (Hunt et al., 1998; 
Shiffman et al., 1999; Goud et al., 2005). The improvements in guideline adherence promoted by the HRs persisted over time, which mitigated the risk that the improvements were temporary and only attributable to reactivity effects. However, the study was restricted to intra-regional CICUs, which are publicly financed and the study focused solely on patients with acute coronary syndrome, which are limitations.

\section{Contextual features}

This study pointed to the barriers to introducing and disseminating innovations in healthcare systems. It may be important to rethink how healthcare systems support employees in bringing their innovative ideas and suggestions for improvement into reality. Difficulties in mobilising funding, insufficient time and knowledge, and an irrelevance to career progression are some factors that may prevent improvement initiatives and innovations (Wong et al., 2000; den Hertog et al., 2005); some were observed during the present intervention, which required much perseverance and overtime for the physician guiding and leading the HRs development and introduction. Moreover, healthcare systems seem to rely excessively on enthusiastic individuals as opposed to creating structures and processes capable of supporting sustained efforts towards innovation and improvement. Despite these difficulties, the initiative was successful and the HRs use continues. Arguably, the intervention being led by a physician who was an insider, may have facilitated the change. Another possible explanation for the successful intervention was the collaboration between the physician and IT developers, which may have enhanced the HRs adequacy for physician needs in daily practice regarding functionality and operational efficiency (Bates et al., 2003; Ash et al., 2004). Adopting the HRs voluntarily may have persuaded physicians to try it. Furthermore, the HRs permitted physicians to deviate from guidelines, something that allowed professional judgement and physician autonomy. The HRs adoption may have been facilitated by the perceived benefits for patient recruitment to clinical trials and for disseminating new research findings in clinical practice. Nevertheless, at the intervention's inception, physicians expressed resistance and doubts; i.e., perceptions that the HRs were an intrusion into clinical practice and that physician competence was being questioned created initial reluctance. These viewpoints, although arguable, may easily emerge in an environment that requires individuals to be nothing but infallible, decisive and autonomous in managing the problems at hand.

\section{Practical implications}

Traditionally, healthcare providers have been managing uncertainty by placing high education and training requirements on individuals who are then given discretion to make independent decisions in specific cases. This approach has merits, although it led to deviations from guidelines and inefficient practices. It seems that the time has come for more standardised care delivery, particularly considering the increasingly complex, multi-professional and multidisciplinary healthcare. Nevertheless, there is the risk that guidelines are mindlessly applied and that poor adherence might be replaced by over-compliance to these guidelines. While CDSSs, such as the HRs, exert some pressure towards standardisation, their main virtue is to assist physicians to cope with the challenges inherent in fast-changing medical knowledge. Another CDSS benefit is a reduced reliance on memory and easier communication between healthcare providers.

Future research and policy

Please note, we print footnotes and end notes only under exceptional circumstances. 
The HRs effect on patient outcomes and cost efficiency require further examination. Studying the pre- and post-intervention physician HRs perceptions and the barriers to developing and introducing the HRs would also be valuable. Another aspect we highlight is the slow pace by which improvement initiatives are disseminated, even when improvements are manifest. Hence, an investigation into the barriers to inter-organisational and intra-organisational HRsdissemination would be highly advisable.

\section{References}

Ash, J.S., Berg, M. and Coiera, E. (2004), 'Some Unintended Consequences of Information Technology in Health Care: The Nature of Patient Care Information System-related Errors', Journal of the American Medical Informatics Association, Vol. 11 No. 2, pp. 104112.

Bates, D.W., Cohen, M., Leape, L.L., Overhage, J.M., Shabot, M.M. and Sheridan, T. (2001), 'Reducing the Frequency of Errors in Medicine Using Information Technology', Journal of the American Medical Informatics Association, Vol. 8 No. 4, pp. 299-308.

Bates, D.W., Kuperman, G.J., Wang, S., Gandhi, T., Kittler, A., Volk, L., Spurr, C., Khorasani, R., Tanasijevic, M. and Middleton, B. (2003), 'Ten Commandments for Effective Clinical Decision Support:Making the Practice of Evidence-based Medicine a Reality', Journal of the American Medical Informatics Association, Vol. 10 No. 6, pp. 523-530.

Berlin, A., Sorani, M. and Sim, I. (2006), 'A taxonomic description of computer-based clinical decision support systems', Journal of Biomedical Informatics, Vol. 39 No. 6, pp. 656-667.

Bryman, A. and Bell, E. (2007), Business Research Methods, $2^{\text {nd }}$ ed., Oxford University Press, New York.

Cabana, M.D., Rand, C.S., Powe, N.R., Wu, A.W., Wilson, M.H., Abboud, P.C. and Rubin, H.R. (1999), 'Why Don't Physicians Follow Clinical Practice Guidelines? A Framework for Improvement', Journal of the American Medical Association, Vol. 282 No. 15, pp. 14581465.

Chassin, M.R. and Galvin, R.W. and National Roundtable on Health Care Quality (1998), 'The Urgent Need to Improve Health Care Quality: Institute of Medicine National Roundtable on Health Care Quality', Journal of the American Medical Association, Vol. 280 No. 11, pp. 1000-1005.

Coiera, E. (2003), Guide to Health Informatics, $2^{\text {nd }}$ ed., Hodder Arnold, London.

Davis, D.A. and Taylor-Vaisey, A. (1997), 'Translating guidelines into practice: A systematic review of theoretic concepts, practical experience and research evidence in the adoption of clinical practice guidelines', Canadian Medical Association Journal, Vol. 157 No. 4, pp. 408-416.

den Hertog, F., Groen, M. and Weehuizen, R. (2005), Mapping Health Care Innovation: tracing walls and ceilings, MERIT-Infonomics Research Memorandum series, Maastricht.

Dexter, P.R., Perkins, S., Overhage, J.M., Maharry, K., Kohler, R.B. and McDonald, C.J. (2001), 'A Computerized Reminder System to Increase the Use of Preventive Care for Hospitalized Patients', New England Journal of Medicine, Vol. 345 No. 13, pp. 965-970.

Eagle, K.A., Garson, A.J., Beller, G.A. and Sennett, C. (2003), 'Closing The Gap Between Science And Practice: The Need For Professional Leadership', Health Affairs, Vol. 22 No. 2, pp. 196-201.

Garg, A.X., Adhikari, N.K.J., McDonald, H., Rosas-Arellano, M.P., Devereaux, P.J., Beyene, J., Sam, J. and Haynes, R.B. (2005), 'Effects of Computerized Clinical Decision Support 
Systems on Practitioner Performance and Patient Outcomes: A systematic review', Journal of the American Medical Association, Vol. 293 No. 10, pp. 1223-1238.

Goud, R., Peek, N., Strijbis, A.M., de Clercq, P.A. and Hasman, A. (2005), 'A Computer-Based Guideline Implementation System for Cardiac Rehabilitation Screening', Computers in Cardiology, Vol. 32 No. 3, pp. 323-326.

Grimshaw, J.M., Shirran, L., Thomas, R., Mowatt, G., Fraser, C., Bero, L., Grilli, R., Harvey, E., Oxman, A. and O'Brien, M.A. (2001), 'Changing Provider Behavior: An Overview of Systematic Reviews of Interventions', Medical Care, Vol. 39 No. 8 Suppl 2, pp. II2-II45.

Grol, R. and Grimshaw, J. (2003), 'From best evidence to best practice: effective implementation of change in patients' care', Lancet, Vol. 362 No. 9391, pp. 1225-1230.

Grønmo, S. (2006), Metoder i samhällsvetenskap, $1^{\text {st }}$ ed., Liber, Malmö, (in Swedish).

Hunt, D.L., Haynes, R.B., Hanna, S.E. and Smith, K. (1998), 'Effects of Computer-Based Clinical Decision Support Systems on Physician Performance and Patient Outcomes: A systematic review', Journal of the American Medical Association, Vol. 280 No. 15, pp. 1339-1346.

Kawamoto, K., Houlihan, C.A., Balas, E.A. and Lobach, D.F. (2005), 'Improving clinical practice using clinical decision support systems: a systematic review of trials to identify features critical to success', British Medical Journal, Vol. 330 No. 7494, pp. 1-8.

Payne, T.H. (2000), 'Computer Decision Support Systems', Chest, Vol. 118 No. 2 Suppl, pp. $47 \mathrm{~S}-52 \mathrm{~S}$.

Prior, M., Guerin, M. and Grimmer-Somers, K. (2008), 'The effectiveness of clinical guideline implementation strategies - a synthesis of systematic review findings', Journal of Evaluation in Clinical Practice, Vol. 14 No. 5, pp. 888-897.

Reckmann, M.H., Westbrook, J.I., Koh, Y., Lo, C. and Day, R.O. (2009), 'Does Computerized Provider Order Entry Reduce Prescribing Errors for Hospital Inpatients?A Systematic Review', Journal of the American Medical Informatics Association, Vol. 16 No. 5, pp. 613-623.

RIKS-HIA. (2005), RIKS-HIA 10 years report 1995-2004, Uppsala Clinical Research Centre, Uppsala.

Sackett, D.L., Rosenberg, W.M., Gray, J.A., Haynes, R.B. and Richardson, W.S. (1996), 'Evidence based medicine: what it is and what it isn't', British Medical Journal, Vol. 312 No. 7023, pp. 71-72.

Schedlbauer, A., Prasad, V., Mulvaney, C., Phansalkar, S., Stanton, W., Lib, D., Bates, D.W. and Avery, A.J. (2009), 'What Evidence Supports the Use of Computerized Alerts and Prompts to Improve Clinicians' Prescribing Behavior?', Journal of the American Medical Informatics Association, Vol. 16 No. 4, pp. 531-538.

Shiffman, R.N., Liaw, Y., Brandt, C.A. and Corb, G.J. (1999), 'Computer-based Guideline Implementation Systems: A Systematic Review of Functionality and Effectiveness', Journal of the American Medical Informatics Association, Vol. 6 No. 2, pp. 104-114.

Shojania, K.G., Jennings, A., Mayhew, A., Ramsay, C., Eccles, M. and Grimshaw, J. (2010), 'Effect of point-of-care computer reminders on physician behaviour: a systematic review', Canadian Medical Association Journal, Vol. 182 No. 5, pp. E216-E225.

Sipkoff, M. (2003), '9 Ways To Reduce Unwarranted Variation', Managed Care, Vol. 12 No. 11, pp. 20-4, 27-8, 30 passim.

Please note, we print footnotes and end notes only under exceptional circumstances. 
Skaraborg. (2012), 'Welcome to Skaraborg Hospital', available at: www.vgregion.se/Skaraborgs-sjukhus/Skaraborgs-sjukhus/Welcome-to-SkaraborgHospital/, accessed October 2012.

SWEDEHEART. (2012), 'SWEDEHEART', available at: www.ucr.uu.se/swedeheart/, accessed October 2012.

Varonen, H., Kortteisto, T. and Kaila, M. (2008), 'What may help or hinder the implementation of computerized decision support systems (CDSSs): a focus group study with physicians', Family Practice, Vol. 25 No. 3, pp. 162-167.

VGR. (2012), 'The good life in Västra Götaland', available at: www.vgregion.se/en/VastraGotalandsregionen/Home/, accessed October 2012.

Wennberg, J.E. (2002), 'Unwarranted variations in healthcare delivery: implications for academic medical centres', British Medical Journal, Vol. 325 No. 7370, pp. 961-964.

Wong, H.J., Legnini, M.W. and Whitmore, H.H. (2000), 'The Diffusion of Decision Support Systems in Healthcare: Are We There Yet?', Journal of Healthcare Management, Vol. 45 No. 4, pp. 240-249.

Wyatt, J.C. and Liu, J.L. (2002), 'Basic concepts in medical informatics', Journal of Epidemiology and Community Health, Vol. 56 No. 11, pp. 808-812.

Table I: Intervention CICU and control group

\begin{tabular}{|c|c|c|}
\hline & Intervention CICU & $\mathrm{Control}^{\#}$ \\
\hline Location & West Sweden & West Sweden \\
\hline Number of inhabitants in service area in $2003^{\S}$ & 276000 & 1239000 \\
\hline Population density in service area in 2003 (inhabitants $\left./ \mathrm{km}^{2}\right)^{\S}$ & 42 & 71 \\
\hline Median gross income per capita in ages $20+$ in 2003 (thousand SEK) ) $^{\S}$ & 193 & 192 \\
\hline Median age in $2003^{\S}$ & 41 & 40 \\
\hline Proportion of population aged $75+$ in $2003^{\S}$ & $9.3 \%$ & $8.9 \%$ \\
\hline Proportion of women in $2003^{\S}$ & $50.5 \%$ & $50.3 \%$ \\
\hline Proportion of unemployed in ages $18-64$ in $2003^{\S}$ & $4.3 \%$ & $5.2 \%$ \\
\hline Proportion of foreign-born inhabitants in $2003^{\S}$ & $10.6 \%$ & $13.8 \%$ \\
\hline Municipal revenues in 2003 (thousands SEK/inhabitant)" & 9.9 & 11.2 \\
\hline Number of beds available per 1000 inhabitant in $2003^{\ddagger}$ & 1.9 & 3.8 \\
\hline
\end{tabular}

Please note, we print footnotes and end notes only under exceptional circumstances. 
Table II: Short- and long-term effects

\begin{tabular}{|c|c|c|c|c|c|c|c|c|}
\hline & \multicolumn{8}{|c|}{ Short-term } \\
\hline \multicolumn{4}{|c|}{ Quality indicator } & \multicolumn{2}{|c|}{ Intervention } & \multicolumn{2}{|l|}{ Control } & $\mathrm{p}$ \\
\hline \multirow{2}{*}{$\% \mathrm{COR}^{\ddagger}$} & \multicolumn{3}{|c|}{ Prescribed in 2002} & \multicolumn{2}{|c|}{$51 \%(\mathrm{~N}=146)$} & \multicolumn{2}{|c|}{$46 \%(\mathrm{~N}=1142)$} & 0.28 \\
\hline & \multicolumn{3}{|c|}{ Prescribed in 2004} & \multicolumn{2}{|c|}{$81 \%(\mathrm{~N}=120)$} & \multicolumn{2}{|c|}{$58 \%(\mathrm{~N}=869)$} & $<0.001$ \\
\hline \multirow[t]{2}{*}{$\% \mathrm{HEP}^{\dagger}$} & \multicolumn{3}{|c|}{ Prescribed in 2002} & \multicolumn{2}{|c|}{$71 \%(\mathrm{~N}=146)$} & \multicolumn{2}{|c|}{$75 \%(\mathrm{~N}=1127)$} & 0.38 \\
\hline & \multicolumn{3}{|c|}{ Prescribed in 2004} & \multicolumn{2}{|c|}{$92 \%(\mathrm{~N}=150)$} & \multicolumn{2}{|c|}{$80 \%(\mathrm{~N}=970)$} & $<0.001$ \\
\hline \multirow{2}{*}{$\% \mathrm{LIP}^{\S}$} & \multicolumn{3}{|c|}{ Prescribed in 2002} & \multicolumn{2}{|c|}{$49 \%(\mathrm{~N}=251)$} & \multicolumn{2}{|c|}{$66 \%(\mathrm{~N}=1768)$} & $<0.001$ \\
\hline & \multicolumn{3}{|c|}{ Prescribed in 2004} & \multicolumn{2}{|c|}{$90 \%(\mathrm{~N}=227)$} & \multicolumn{2}{|c|}{$73 \%(\mathrm{~N}=1677)$} & $<0.001$ \\
\hline \multirow{2}{*}{$\% \mathrm{ACE}^{\S}$} & \multicolumn{3}{|c|}{ Prescribed in 2002} & \multicolumn{2}{|c|}{$46 \%(N=251)$} & \multicolumn{2}{|c|}{$50 \%(\mathrm{~N}=1771)$} & 0.17 \\
\hline & \multicolumn{3}{|c|}{ Prescribed in 2004} & \multicolumn{2}{|c|}{$89 \%(\mathrm{~N}=163)$} & \multicolumn{2}{|c|}{$64 \%(\mathrm{~N}=1203)$} & $<0.001$ \\
\hline \multicolumn{9}{|c|}{ control group of seven CICUs; ${ }^{\S}$ control group of eight CICUs } \\
\hline \multicolumn{9}{|c|}{ Long-term } \\
\hline \multirow{2}{*}{$\begin{array}{c}\text { Quality } \\
\text { indicator }\end{array}$} & $\begin{array}{r}\text { Weighted g } \\
(\mathrm{N}=\text { Ave }\end{array}$ & $\begin{array}{l}\text { ideline adhere } \\
\text { ge number of }\end{array}$ & $\begin{array}{l}\text { ce over } 2 \\
\text { eligible pe }\end{array}$ & $\begin{array}{l}04-2008^{11} \\
\text { year) }\end{array}$ & & $\begin{array}{l}\text { hange in } \\
s \text { at }\end{array}$ & Annu & hange in \\
\hline & Intervention & Control & $\mathrm{p}$ & $\begin{array}{c}\mathrm{OR} \\
{\left[\mathrm{CI}_{95 \%}\right]}\end{array}$ & & $\begin{array}{l}\text { ention } \\
\left.\text { nto }^{\S}\right]^{\S}\end{array}$ & grol & $\left.\mathrm{CI}_{95 \%}\right]^{+}$ \\
\hline$\% \mathrm{COR}^{\#}$ & $\begin{array}{c}83 \% \\
(\mathrm{~N}=99)\end{array}$ & $\begin{array}{c}62 \% \\
(\mathrm{~N}=948)\end{array}$ & $<0.001$ & $\begin{array}{l}1.2 \\
{[1.1,1.2]}\end{array}$ & $13^{\circ}$ & $\%, 33 \%]$ & $-11 \%$ & $5 \%,-7 \%]$ \\
\hline$\% \mathrm{HEP}^{\#}$ & $\begin{array}{c}96 \% \\
(\mathrm{~N}=100)\end{array}$ & $\begin{array}{c}89 \% \\
(\mathrm{~N}=1210)\end{array}$ & $<0.001$ & $\begin{array}{l}1.2 \\
{[1.2,1.3]}\end{array}$ & $43^{\circ}$ & \%,101\%] & $-11 \%$ & $7 \%,-4 \%]$ \\
\hline$\% \mathrm{LIP}^{\#}$ & $\begin{array}{c}94 \% \\
(\mathrm{~N}=238)\end{array}$ & $\begin{array}{c}84 \% \\
(\mathrm{~N}=1978)\end{array}$ & $<0.001$ & $\begin{array}{l}1.3 \\
{[1.3,1.4]}\end{array}$ & & $\%, 46 \%]$ & $-26 \%$ & $\%,-23 \%]$ \\
\hline$\% \mathrm{ACE}^{\#}$ & $\begin{array}{c}91 \% \\
(\mathrm{~N}=180)\end{array}$ & $\begin{array}{c}74 \% \\
(\mathrm{~N}=1427)\end{array}$ & $<0.001$ & $\begin{array}{l}1.2 \\
{[1.1,1.2]}\end{array}$ & $12^{\circ}$ & $\%, 32 \%]$ & $-14 \%$ & $7 \%,-10 \%]$ \\
\hline$\% \mathrm{CLO}^{\#}$ & $\begin{array}{c}87 \% \\
(\mathrm{~N}=102)\end{array}$ & $\begin{array}{c}65 \% \\
(\mathrm{~N}=1031)\end{array}$ & $<0.001$ & $\begin{array}{l}1.7 \\
{[1.6,1.7]}\end{array}$ & & $\%, 59 \%]$ & $-39 \%$ & $\%,-36 \%]$ \\
\hline
\end{tabular}

\# control group: ten CICUs; ${ }^{\text {| }}$ weighted by annual eligible patients; ${ }^{\S}$ annual change in odds of being prescribed the recommended therapy at the intervention CICU; ${ }^{\ddagger}$ annual change in odds of being prescribed the recommended therapy in the control group in relation to the intervention CICU

Figure 1: The HRs screenshot

Please note, we print footnotes and end notes only under exceptional circumstances. 


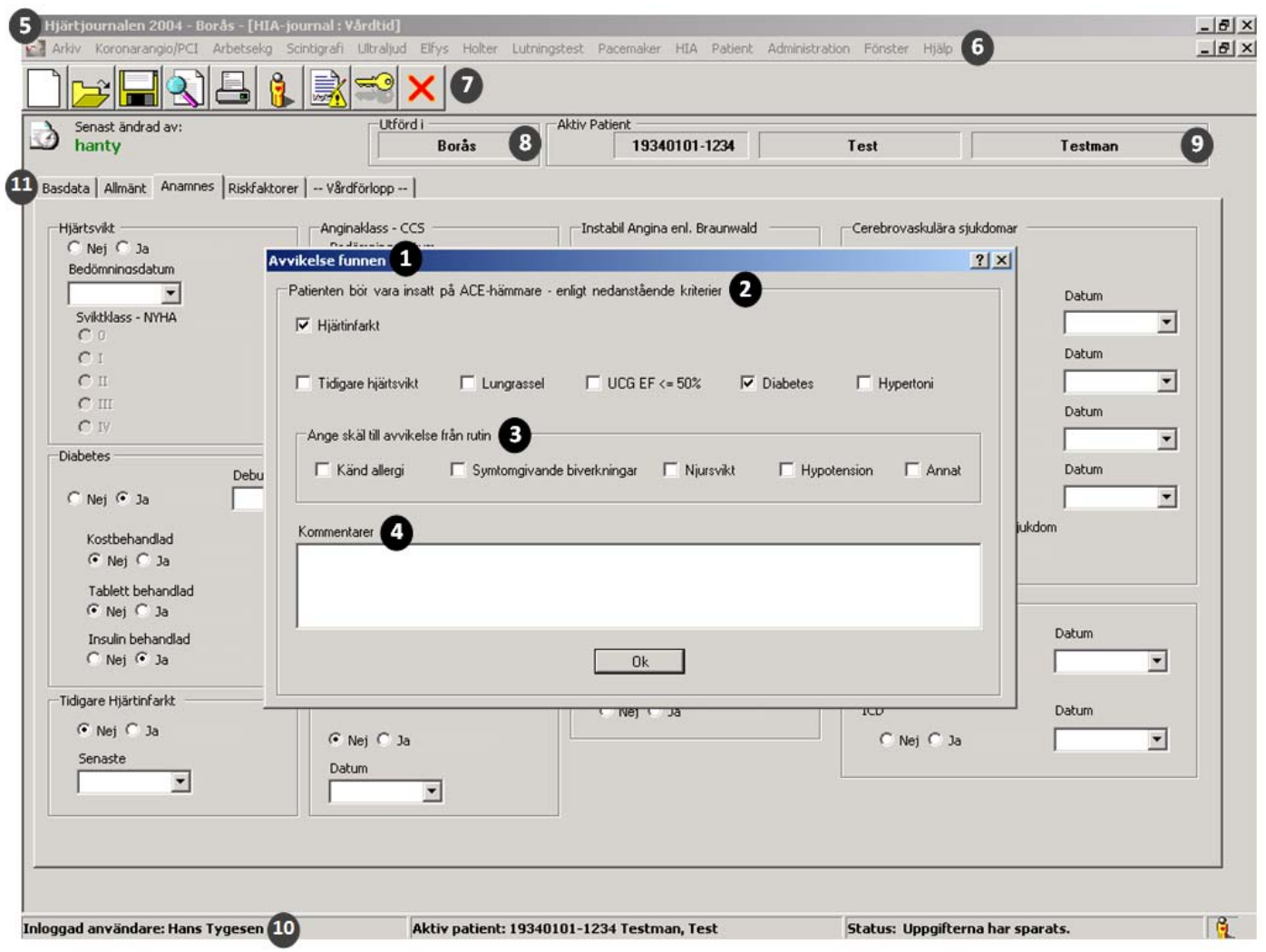

Please note, we print footnotes and end notes only under exceptional circumstances. 
Figure 2: Short-term effects on: \%COR, \%HEP, \%LIP and \%ACE.

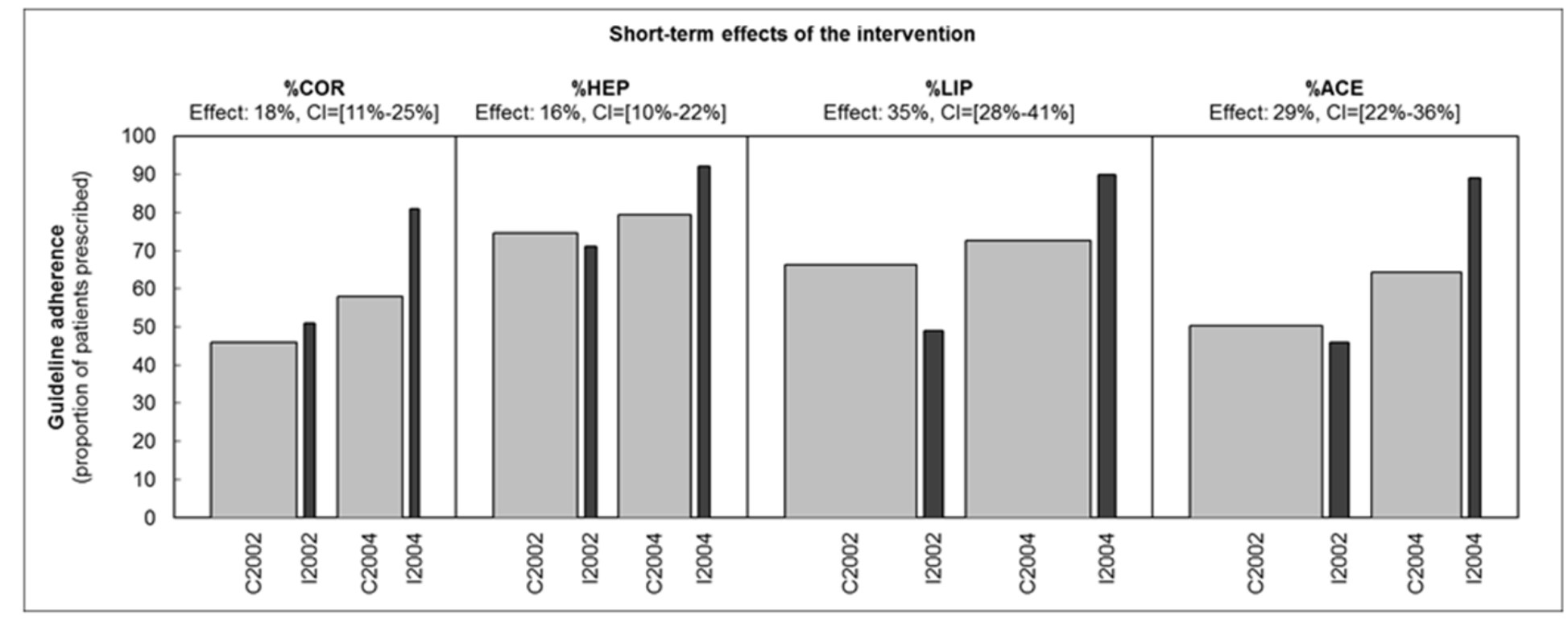

Please note, we print footnotes and end notes only under exceptional circumstances. 
Figure 3: Long-term effects on: \%COR, \%HEP, \%LIP, \%ACE and \%CLO quality indicators.

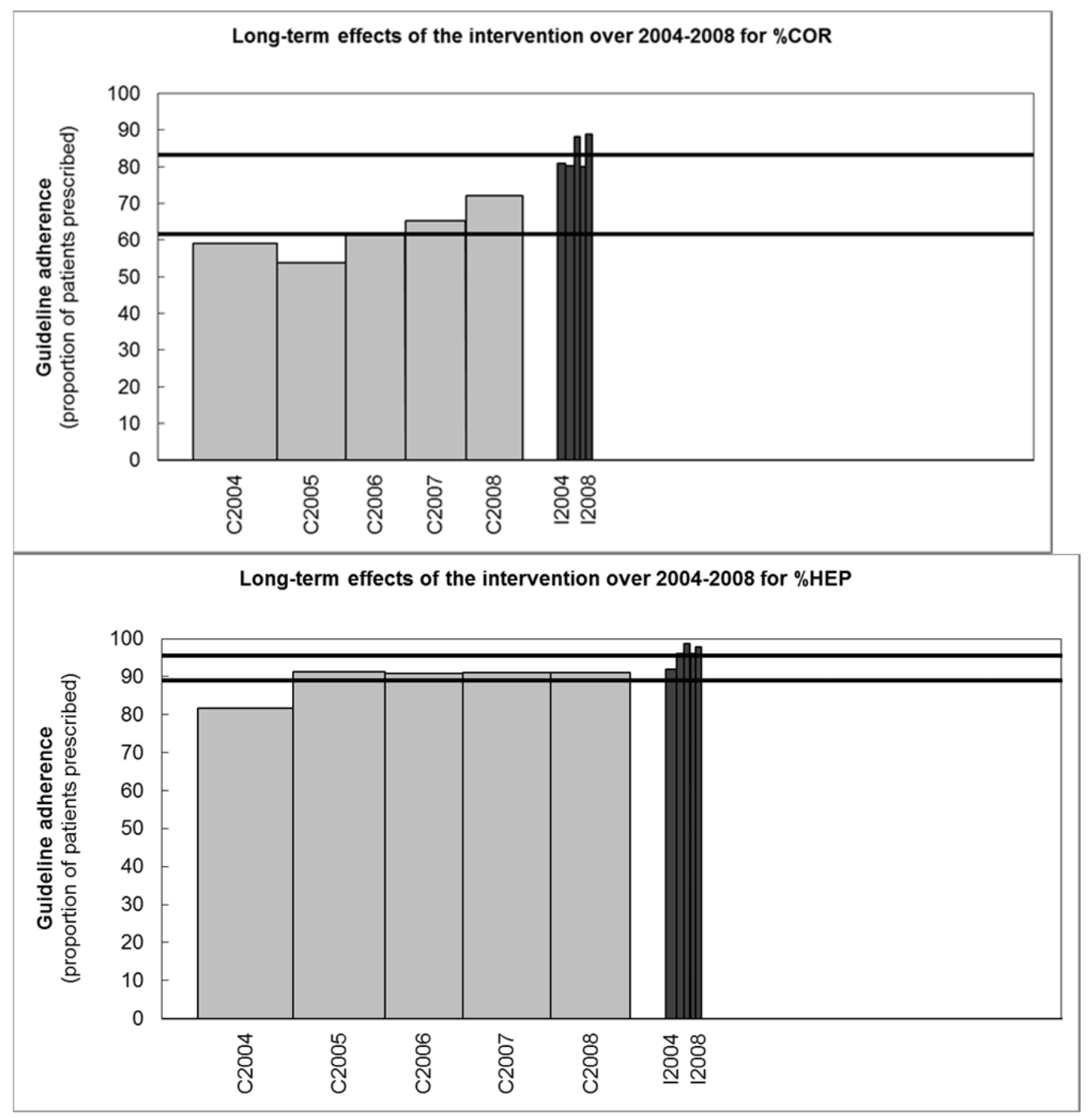

14

Please note, we print footnotes and end notes only under exceptional circumstances. 


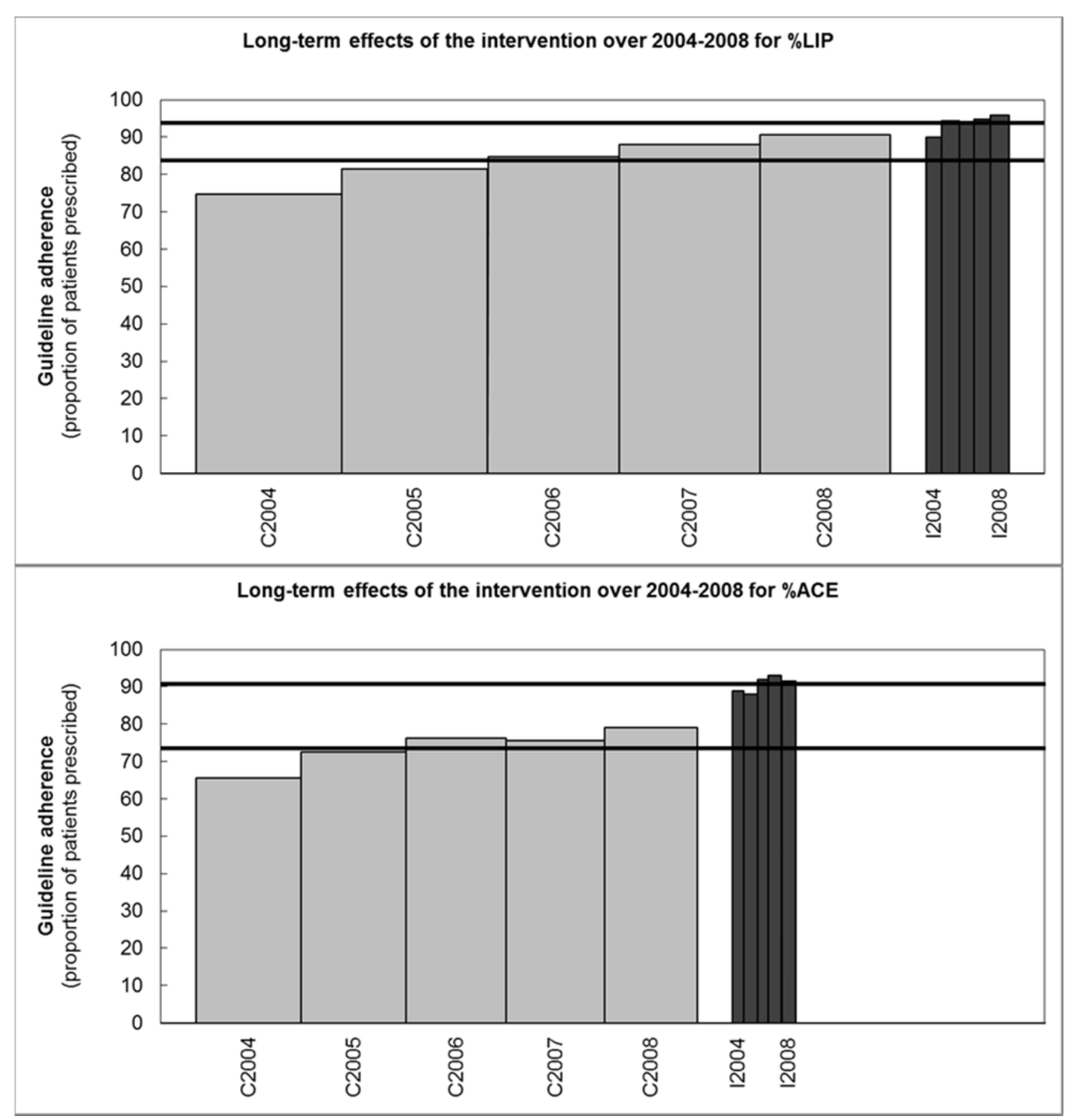

15

Please note, we print footnotes and end notes only under exceptional circumstances. 


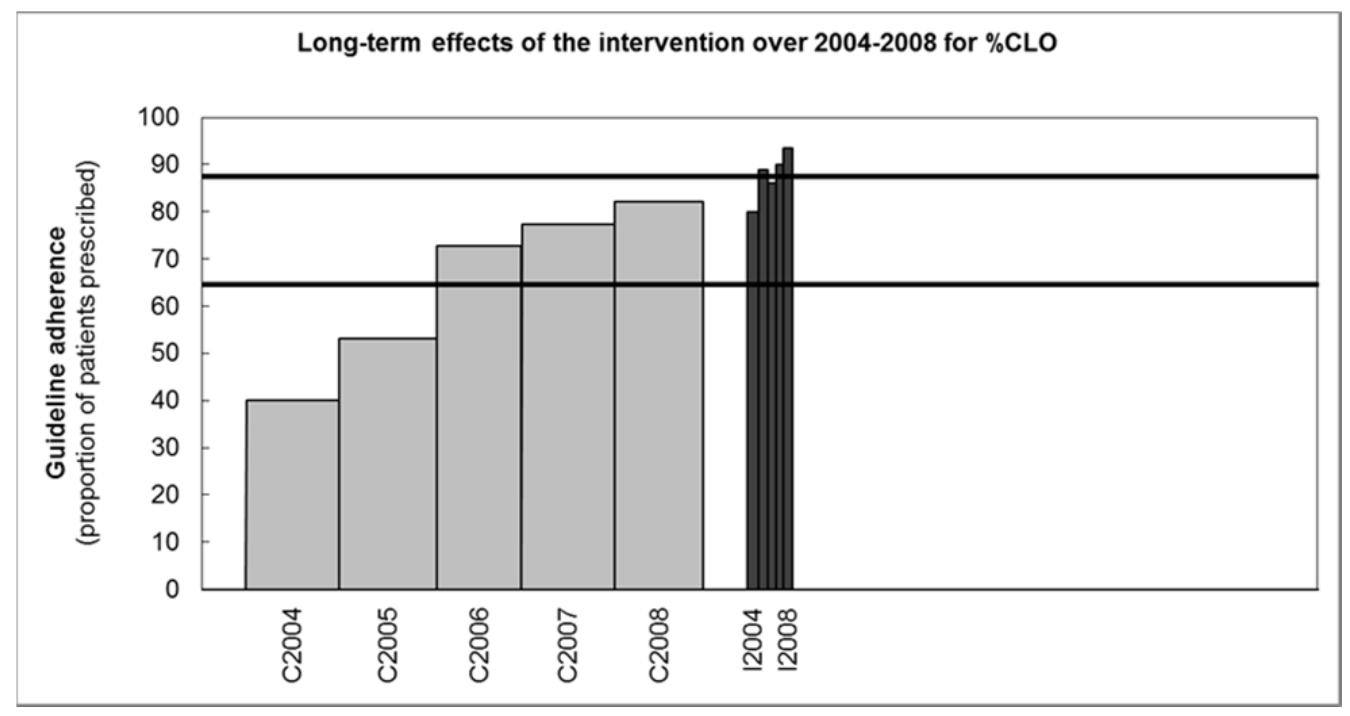

Please note, we print footnotes and end notes only under exceptional circumstances. 


\begin{tabular}{|c|c|c|c|c|c|c|c|c|c|c|c|}
\hline \multicolumn{6}{|c|}{ AS COUNTS } & \multicolumn{6}{|c|}{ AS PERCENTAGES } \\
\hline & \multicolumn{2}{|c|}{ OBSERVED } & \multirow[b]{2}{*}{ Total } & & & & \multicolumn{2}{|l|}{ OBSERVED } & \multirow[b]{2}{*}{ Total } & & \\
\hline & Yes & No & & & & & Yes & No & & & \\
\hline Intervention & 10 & 90 & 100 & $p=$ & $10 \%$ & Intervention & 0,1 & 0,9 & 1 & $p=$ & $=10 \%$ \\
\hline Control & 50 & 150 & 200 & $p=$ & $25 \%$ & Control & 0,25 & 0,75 & 1 & $p=$ & $=25 \%$ \\
\hline \multirow[t]{4}{*}{ Total } & 60 & 240 & 300 & $p=$ & $20 \%$ & Total & 0,35 & 1,65 & 2 & $p=$ & $=18 \%$ \\
\hline & & & & & & & & & & & \\
\hline & \multicolumn{3}{|c|}{ EXPECTED IF NO DIFFERENCE } & & & & \multicolumn{3}{|c|}{ EXPECTED IF NO DIFFERENCE } & & \\
\hline & Yes & No & Total & & & & Yes & No & Total & & \\
\hline Intervention & 20 & 80 & 100 & $p=$ & $20 \%$ & Intervention & 0,175 & 0,825 & 1 & $p=$ & $=18 \%$ \\
\hline Control & 40 & 160 & 200 & $p=$ & $20 \%$ & Control & 0,175 & 0,825 & 1 & $p=$ & $=18 \%$ \\
\hline \multirow[t]{6}{*}{ Total } & 60 & 240 & 300 & $p=$ & $20 \%$ & Total & 0,35 & 1,65 & 2 & $p=$ & $=18 \%$ \\
\hline & & & & & & & & & & & \\
\hline & 5 & 1,25 & & & & & 0,032143 & 0,006818 & & & \\
\hline & 2,5 & 0,625 & & & & & 0,032143 & 0,006818 & & & \\
\hline & \multicolumn{2}{|c|}{ Chi-square statistic } & 9,375 & & & & \multicolumn{2}{|c|}{ Chi-square statistic } & 0,077922 & & \\
\hline & \multicolumn{2}{|c|}{ Degress of freedom } & 1 & & & & \multicolumn{2}{|c|}{ Degress of freedom } & 1 & & \\
\hline
\end{tabular}

Please note, we print footnotes and end notes only under exceptional circumstances. 